\title{
Self-Reported Flushing and Genotypes of ALDH2, ADH2, and ADH3 among Taiwanese Han
}

\author{
Wei J. Chen, Chiao-Chicy Chen, Jeng-Ming Yu, and Andrew T. A. Cheng
}

\begin{abstract}
The aims of this study are to investigate whether self-reported facial flushing postalcohol consumption (PAC) among subjects with ALDH2* $1 /{ }^{*} 1$ can be attributed to ADH2 or $A D H 3$ and whether the prediction of ALDH2 genotype can be improved by examining the combination of flushing and other accompanying reactions of PAC sensitivity. Fifty-eight subjects of Han ancestry in Taiwan were interviewed for alcohol-sensitivity reactions and their blood samples were genotyped for ALDH2, ADH2, and ADH3. For subjects with ALDH $2^{*} 1 /{ }^{*} 1(n=46), 70 \%$ reported to have no flushing PAC and $30 \%$ reported flushing PAC. When subjects with ALDH2*1/*1 had ADH2*1/*1 $(n=11)$, all reported to have no flushing; otherwise, $35 \%$ (for $\mathrm{ADH}^{*} 1 /{ }^{*} 2, n=17$ ) and $44 \%$ (for $A D H 2 * 2 / * 2, n=18$ ) reported flushing. For subjects with ALDH2*1/*1 and at least one ADH2*2 allele, the genotype of $A D H 3$ was not associated with self-reported flushing. PAC flushers with ALDH2*1/*1 $(50 \%)$ were more likely to report nausea than those with ALDH2*1/*2 $(8 \%)$. The probability of ALDH2 $2^{*} 1 / * 1$ given flushing reported was 0.29 , while the probability of ALDH $2 * 1 / * 1$ given both flushing and nausea reported was 0.71 . The results indicate that self-reported flushing is determined by both ALDH2 and ADH2 and that prediction of ALDH2 genotype on the basis of self-reported flushing and nausea can help identify subjects at increased risk for alcoholism.
\end{abstract}

Key Words: Acetaldehyde, Alcohol Sensitivity, Alcoholism, Nausea.

$\mathbf{F}$ ACIAL FLUSHING after consumption of alcohol, following a seminal study of Wolff, ${ }^{1}$ has been found to be more commonly seen in various Asian populations (48$75 \%$ ) than in Caucasians (3-29\%). ${ }^{2}$ Many symptoms other than facial flushing after the consumption of alcohol, such as tachycardia, headache, and nausea, have also been reported. ${ }^{2}$ Self-reported flushing has been found to be associated with decreased alcohol use and abuse. ${ }^{3-9}$ Thus the higher rate of alcohol-induced flushing has been postulated as a physiological explanation for the lower prevalence of alcoholism in Asian populations. In these populations, flushing was found to exhibit familial resemblance, al-

From Institute of Epidemiology, College of Public Health, National Taiwan University (W.J.C.); Department of Adult Psychiatry, Taipei City Psychiatric Center (C.C.C., J.M.Y.); and Division of Epidemiology and Public Health, Institute of Biomedical Sciences, Academia Sinica (A.T.A.C.), Taipei, Taiwan.

Received for publication July 23, 1997; accepted March 4, 1998

This work was supported by grants from the National Science Council, Taipei (NSC 83-0203-B001-102, NSC 84-2331-B001-046, NSC 85-2331B002-345-M31).

Reprints requests: Dr. Andrew T.A. Cheng, Division of Epidemiology and Public Health, Institute of Biomedical Sciences, Academia Sinica, Taipei, Taiwan.

Copyright (C) 1998 by The Research Society on Alcoholism. 1048 though the pattern cannot be explained by a single gene model. ${ }^{10-13}$

In humans, alcohol is first oxidized by alcohol dehydrogenase $(\mathrm{ADH})$ into acetaldehyde, which is then oxidized by aldehyde dehydrogenase (ALDH) into acetate. Increased steady-state blood acetaldehyde levels have been implicated to mediate the alcohol-induced facial flushing in Japanese and Chinese subjects. ${ }^{14-16}$ Thus, differences in alcohol sensitivity in individuals might result from genetic polymorphisms in the enzymes that lead to either fast production or slow elimination of acetaldehyde after consumption of alcohol. The genetic polymorphisms of the alcohol-metabolizing genes arise mainly from $\mathrm{ADH} 2$, $\mathrm{ADH} 3$, and ALDH $2 .{ }^{17,18}$ The kinetic differences among $\mathrm{ADH} 2$ isozymes are much more striking than those among the ADH3 isozymes. For example, the maximum rate of reaction $\left(V_{\max }\right.$ ) of $\beta_{2}$ (encoded by $\mathrm{ADH} 2 * 2$ ) homodimers is around 40 times that of $\beta_{1}$ (encoded by $\mathrm{ADH} 2 * 1$ ) homodimers, while the $V_{\max }$ of $\gamma_{1}$ (encoded by ADH3*1) homodimers is double that of $\gamma_{2}$ (encoded by ADH3*2) homodimers. ${ }^{17}$ A point mutation in ALDH2 produces a deficiency in ALDH2 activity. Hepatic ALDH2 activity is absent and metabolism of acetaldehyde is severely impaired in people homozygous for ALDH2*2, while in those heterozygous for ALDH2*2 the lack of hepatic ALDH2 activity is partial and metabolism of acetaldehyde is mildly impaired. ${ }^{19}$

Similar to early studies on facial flushing and alcoholism, the alcohol-metabolizing genes, especially ALDH2 and $\mathrm{ADH} 2$, have been consistently demonstrated to be associated with an elevated risk of alcoholism in various Asian populations. ${ }^{20-24} \mathrm{We}$ have recently demonstrated that all three alcohol-metabolizing genes have an independent effect on increasing the risk of alcoholism in Taiwanese Han, with ALDH2*1 having the highest effect, followed by $\mathrm{ADH} 2 * 1$ and $\mathrm{ADH} 3 * 2{ }^{25}$ Thus, it is natural to posit that individual differences in flushing postalcohol consumption (PAC) is mainly due to genetic polymorphisms in ALDH2, while in a relatively small proportion of subject differences are due to polymorphisms in $\mathrm{ADH} 2$ or $\mathrm{ADH} 3$.

Few studies have examined the relationship between self-reported flushing and genotypes of alcoholmetabolizing genes. Two studies of Japanese subjects found that ALDH2 genotype was associated with flushing while $\mathrm{ADH} 2$ genotype was not. ${ }^{26,27}$ One study among American college students of Asian descent found that investigator- 
observed flushing is very accurate in predicting ALDH2 genotype, while self-reported flushing tends to overestimate ALDH $2 * 1 /{ }^{*} 2{ }^{28}$ Two important issues remain to be determined: whether self-reported flushing among subjects with ALDH $2 * 1 /{ }^{*} 1$ can be explained by a contribution from $\mathrm{ADH} 2$ or $\mathrm{ADH} 3$, and whether the prediction of ALDH2 genotype can be improved by detecting the presence of flushing in combination with other accompanying reactions of alcohol sensitivity. In this study we investigated these two issues in 58 subjects of Han ancestry in Taiwan by assessing their ALDH2, ADH2, and ADH3 genotypes and their PAC sensitivity reactions.

\section{METHODS}

Subjects were all of Han ancestry and part of a case-control study of alcoholism and its candidate genes. The ascertainment of the subjects has been described in detail elsewhere. ${ }^{25,29}$ Briefly, subjects who met the DSM-III- $\mathrm{R}^{30}$ criteria of alcohol dependence with withdrawal symptoms were included as cases. The controls were subjects who had no alcohol problems and were matched on the basis of ethnicity and sex to cases. Older eligible subjects were preferred as matched controls to avoid misclassification in phenotype. The alcoholic status of the subjects was assessed by a psychiatrist or a well-trained research assistant with a semistructured clinical interview for alcoholism. The reliability of the instrument has been reported to be satisfactory. ${ }^{31}$. The Han alcoholic subjects were recruited from both community (Chinshan and Sanchi Township) and clinical settings (Taipei City Psychiatric Center and Chinshan Health Station) in northern Taiwan, while the Han controls were recruited from both the community (Chinshan and Sanchi Township) and the Health Screening Ward at National Taiwan University Hospital. Controls who were abstainers or never consumed a significant amount of alcohol were excluded for this study. In total, 49 alcoholic cases (46 men and 3 women) and 9 controls ( 7 men and 2 women) were included for this study. The mean age and standard deviation for cases was $42.0 \pm 9.3$ years (ranging from 23 to 68 years), while that for controls was $66.3 \pm 9.4$ years (ranging from 43 to 75 ).

The semistructured clinical interview included a section on reactions to alcohol consumption. Reactions inquired included: facial flushing, tachycardia, dizziness, headache, sweating, nausea, itching, agitation, sleepiness, and weakness. Possible responses to this inquiry were "never," "ever" after a small amount of alcohol (less than one drink of spirits [15 ml], two drinks of wine, or $150 \mathrm{ml}$ of beer), and "ever" after more than such a small amount of alcohol. For the purpose of this study, all response reactions were dichotomized into never and ever. Because patterns of flushing might have changed after a prolonged period of alcohol drinking, we reminded our subjects in the interview that we were looking for alcohol sensitivity reactions PAC at an early year of alcohol drinking if they recently have been or currently are frequent or heavy drinkers.

After informed consent was obtained, $30 \mathrm{ml}$ of venous blood were drawn from each participant. Ten milliliters were used for the isolation of leukocyte DNA according to a standard protocol or with the commercial kit GENOMIX (Talent, Italy). The genotyping of the ADH2, ADH3, and ALDH2 have been described in detail elsewhere. ${ }^{25}$ Briefly, we followed the method of $\mathrm{Xu}$ et $\mathrm{al}^{32}$ for the genotyping of $\mathrm{ADH} 2$, the method of Walzer et al. ${ }^{33}$ for the genotyping of $\mathrm{ADH} 3$, and the method of Tu and Israel $^{34}$ for the genotyping of ALDH2. All polymerase chain reactions were conducted in a GeneAmp PCR System 9600.

The differences in the percentage of responses between subjects of different genotypes were examined by Fisher's exact test (2-tail). Predictive probability of a subject with a particular ALDH2 genotype given one or two alcohol sensitivity reactions was calculated according to Bayes's theorem. Denoting the number of ALDH 2 genotypes as $n$, the probability
Table 1. Self-Report of Flushing after Consumption of Alcohol and ALDH2 Genotype in All Subjects $(n=58)$

\begin{tabular}{lccc}
\hline & $\begin{array}{c}\text { ALDH2*1/*1 } \\
(n=46)\end{array}$ & $\begin{array}{c}\text { ALDH2*1/*2 } \\
(n=12)\end{array}$ & $\begin{array}{c}p \text { Value } \\
\text { (Fisher's exact test) }\end{array}$ \\
\hline Flushing (+) & $14(30 \%)$ & $12(100 \%)$ & \\
Flushing (-) & $32(70 \%)$ & $0(0 \%)$ & $<0.0001$ \\
\hline
\end{tabular}

Table 2. Self-Report of Flushing after Consumption of Alcohol and ADH2 Genotype in Subjects with ALDH2* $1 / * 1(n=46)$

\begin{tabular}{lcccc}
\hline & $\begin{array}{c}\mathrm{ADH} 2^{*} 1 /{ }^{*} 1 \\
(n=11)\end{array}$ & $\begin{array}{c}\mathrm{ADH} 2^{*} 1{ }^{*} 2 \\
(n=17)\end{array}$ & $\begin{array}{c}\mathrm{ADH} 2^{*} 2 / * 2 \\
(n=18)\end{array}$ & $\begin{array}{c}p \text { Value } \\
\text { (Fisher's exact test) }\end{array}$ \\
\hline Flushing $(+)$ & $0(0 \%)$ & $6(35 \%)$ & $8(44 \%)$ & \\
Flushing $(-)$ & $11(100 \%)$ & $11(65 \%)$ & $10(56 \%)$ & 0.023 \\
\hline
\end{tabular}

Tabie 3. Self-Report of Flushing after Consumption of Alcohol and ADH3 Genotype in Subjects with ALDH2*1/*1 and at Least One ADH2*2 (n=35)

\begin{tabular}{lccc}
\hline & $\begin{array}{c}\mathrm{ADH}^{*} 1{ }^{* 1} \\
(n=29)\end{array}$ & $\begin{array}{c}\mathrm{ADH}^{*} 1 /{ }^{* 2} \\
(n=6)\end{array}$ & $\begin{array}{c}p \text { Value } \\
\text { (Fisher's exact test) }\end{array}$ \\
\hline Flushing (+) & $12(41 \%)$ & $2(33 \%)$ & \\
Flushing (-) & $17(59 \%)$ & $4(67 \%)$ & 0.70 \\
\hline
\end{tabular}

of a subject with the $j$ th ALDH2 genotype $\left(G_{j}\right)$ given a positive flushing (F) response was calculated as follows:

$$
\operatorname{prob}\left(G_{j} \mid \mathrm{F}\right)=\frac{\operatorname{prob}\left(G_{j}\right) \cdot \operatorname{prob}\left(\mathrm{F} \mid G_{j}\right)}{\sum_{i=1}^{n} \operatorname{prob}\left(\mathrm{F} \mid G_{i}\right) \cdot \operatorname{prob}\left(G_{i}\right)}
$$

The probability of a subject with the $j$ th ALDH2 genotype $\left(G_{j}\right)$ given positive responses of both flushing $(\mathrm{F})$ and nausea $(\mathrm{N})$ was calculated as follows:

$$
\operatorname{prob}\left(G_{j} \mid \mathrm{F}, \mathrm{N}\right)=\frac{\operatorname{prob}\left(G_{j}\right) \cdot \operatorname{prob}\left(\mathrm{N} \mid G_{j}, \mathrm{~F}\right) \operatorname{prob}\left(\mathrm{F} \mid G_{j}\right)}{\sum_{i=1}^{n} \operatorname{prob}\left(\mathrm{F}, \mathrm{N} \mid G_{i}\right) \cdot \operatorname{prob}\left(G_{i}\right)}
$$

\section{RESULTS}

The genotype of ALDH2 for the subjects in this study were either $\mathrm{ALDH} 2 * 1 /{ }^{*} 1$ or $\mathrm{ALDH} 2 * 1 /{ }^{*} 2$ (Table 1 ). In predicting self-reported flushing on the basis of ALDH2 genotype, subjects with ALDH2*1/*2 all reported to have flushing PAC. For subjects with ALDH2*1/*1, $70 \%$ of them reported to never experience flushing and $30 \%$ reported flushing. To clarify why those with ALDH2*1/*1 have flushing, we classified them further by $\mathrm{ADH} 2$ genotype (Table 2). When subjects with ALDH2* $1 /{ }^{*} 1$ had $\mathrm{ADH} 2 * 1 / * 1$, they all reported to never have flushing; otherwise, $35 \%$ (for $\mathrm{ADH} 2 * 1 /{ }^{*} 2$ ) and $44 \%$ (for $\mathrm{ADH} 2 * 2 /{ }^{*} 2$ ) of subjects with ALDH $2 * 1 /{ }^{*} 1$ reported to have flushing. By examining those with $\mathrm{ALDH} 2 * 1 /{ }^{*} 1$ and at least one $\mathrm{ADH} 2 * 2$ allele, the genotype of $\mathrm{ADH} 3$ was not associated with self-reported flushing (Table 3 ).

Relationships between ALDH2 genotype and selfreported alcohol related responses other than facial flushing are displayed in Table 4. The differences in responses between the two groups of subjects with different ALDH2 genotype were less clear-cut than the difference in facial 
Table 4. Responses, Other than Facial Flushing, after Consumption of Alcohol and ALDH2 Genotype in All Subjects $(\boldsymbol{n}=\mathbf{5 8})$

\begin{tabular}{lccc}
\hline & $\begin{array}{c}\text { ALDH2*1/*1 } \\
(n=46)\end{array}$ & $\begin{array}{c}\text { ALDH2*1/*2 } \\
(n=12)\end{array}$ & $\begin{array}{c}p \text { Value } \\
\text { (Fisher's exact test) }\end{array}$ \\
\hline Tachycardia & $17(38 \%)^{\star}$ & $7(64 \%)^{\star}$ & 0.18 \\
Dizziness & $14(31 \%)^{\star}$ & $4(33 \%)$ & 1.00 \\
Headache & $3(7 \%)^{*}$ & $4(33 \%)$ & $0.03 \ddagger$ \\
Sweating & $6(14 \%)+$ & $2(17 \%)$ & 1.00 \\
Nausea & $12(26 \%)$ & $1(8 \%)$ & 0.26 \\
Itching & $0(0 \%)$ & $0(0 \%)$ & \\
Agitation & $9(20 \%)^{*}$ & $2(17 \%)$ & 1.00 \\
Sleepiness & $23(51 \%)^{\star}$ & $9(75 \%)$ & 0.20 \\
Weakness & $13(29 \%)^{*}$ & $4(33 \%)$ & 0.74 \\
\hline
\end{tabular}

* Data missing in one subject.

+ Data missing in two subjects.

$\ddagger \rho$ value $<0,05$

Table 5. Responses, Other than Facial Flushing, after Consumption of Alcohol and ALDH2 Genotype in Subjects with Flushing $(n=26)$

\begin{tabular}{llcc}
\hline Facial flushing plus & $\begin{array}{c}\text { ALDH2 } \\
(n=14)\end{array}$ & $\begin{array}{c}\text { ALDH2*1/*2 } \\
(n=12)\end{array}$ & $\begin{array}{c}p \text { Value } \\
\text { (Fisher's exact test) }\end{array}$ \\
\hline Tachycardia & $5(38 \%)^{*}$ & $7(64 \%)^{*}$ & 0.41 \\
Dizziness & $5(38 \%)^{*}$ & $4(33 \%)$ & 1.00 \\
Headache & $1(8 \%)^{*}$ & $4(33 \%)$ & 0.16 \\
Sweating & $3(25 \%) \dagger$ & $2(17 \%)$ & 1.00 \\
Nausea & $7(50 \%)$ & $1(8 \%)$ & $0.04 \ddagger$ \\
Itching & $0(0 \%)$ & $0(0 \%)$ & \\
Agitation & $3(23 \%)^{*}$ & $2(17 \%)$ & 1.00 \\
Sleepiness & $5(38 \%)^{*}$ & $9(75 \%)$ & 0.11 \\
Weakness & $3(23 \%)^{*}$ & $4(33 \%)$ & 0.67 \\
\hline
\end{tabular}

* Data missing in one subject.

† Data missing in two subjects.

$\ddagger p$ value $<0.05$

flushing. In general, subjects with $\operatorname{ALDH} 2 * 1 / 22$ tended to report more PAC responses than subjects with ALDH2*1/ ${ }^{*} 1$, except in the case of nausea, in which subjects with ALDH $2 * 1 /{ }^{*} 1$ tended to report a higher rate. Only the response to headaches reported between the two groups was significant.

Since subjects who reported to have facial flushing PAC could be either ALDH $2 * 1 /{ }^{*} 1$ or $\operatorname{ALDH} 2 * 1 /{ }^{*} 2$, whether a response other than facial flushing PAC could differentiate the two genotypes was examined (Table 5). Interestingly, for those who self-reported flushing PAC, subjects with ALDH $2^{*} 1 /{ }^{*} 1$ had a higher percentage reporting of nausea $(50 \%)$ than those with ALDH2*1/*2 (8\%). Meanwhile, the percentage of self-reporting flushers with ALDH $2 * 1 / * 2$ tended to have a higher percentage reporting of headache and sleepiness than that of self-reporting flushers with $\operatorname{ALDH} 2 * 1 /{ }^{*} 1$, although the differences were not significant. If the analyses were limited to alcoholics only, subjects with ALDH2*1/*1 still had a higher percentage reporting of nausea $(6$ out of $9,67 \%)$ than those with ALDH2*1/*2 ( 1 out of $8,13 \%$ ) ( $p=0.05$, Fisher's exact test, 2-tailed).

In calculating the predictive probability of ALDH $2 * 1 /{ }^{*} 1$ given a positive response of flushing for a person in the general population, we set the probability of genotype $\operatorname{ALDH} 2 * 1 /{ }^{*} 1$ to be 0.577 according to the allele frequency of ALDH2* $1^{25}$ under Hardy-Weinberg Equilibrium. Since frequency of $\operatorname{ALDH} 2 * 2 / * 2$ was small $(6 \%)$ in the general population and we did not have such subjects in our sam- ple, we combined ALDH $2 * 1{ }^{*} 2$ and ALDH $2 * 2 / 2$ as one group in the calculation. The conditional probability of self-reported flushing and nausea was 0.15 for subjects with ALDH2 ${ }^{*} 1{ }^{*} 1$ and 0.083 for subjects with ALDH2* $1{ }^{*} 2$. In this way, the probability of a subject with ALDH2*1/*1 given a positive response of flushing is calculated to be 0.29 , while the probability of a subject with $\operatorname{ALDH} 2 * 1 /{ }^{*} 1$ given positive responses of both flushing and nausea is calculated to be 0.71 . If we considered only subjects with ALDH2* $1 /{ }^{*} 1$ and ALDH2 ${ }^{*} 1 /{ }^{*} 2$, the predictive probabilities of ALDH $2 * 1 /{ }^{*} 1$ remained similar: 0.32 given a positive response of flushing and 0.74 given positive responses of flushing and nausea.

If the analyses were limited to men only (i.e., 5 women were excluded), results similar to those of Tables 1 to 5 were obtained except that for those who self-reported flushing PAC, the difference in the percentage reporting of nausea for subjects with ALDH2*1/*1 (6 out of $13,46 \%$ ) and for those with ALDH2* $1 /{ }^{*} 2(1$ out of $10,10 \%)$ became borderline ( $p=0.09$, Fisher's exact test, 2-tailed).

\section{DISCUSSION}

In comparing our results to those of previous studies, ${ }^{26-28}$ it is important to recognize that the subjects examined in all these studies were not a random sample of the general population. Furthermore, alcoholic subjects were not excluded in this study as were in previous studies. Thus, it is not appropriate to compare the probability of flushing in the total sample. An appropriate comparison is on the conditional probability of reporting flushing given a person's ALDH2 genotype. Such conditional probabilities can then be used to predict probability of an ALDH2 genotype given a person's flushing response. This is similar to studies of diagnostic accuracy in which investigators report sensitivity of a test on the basis of a sample of patients and nonpatients. The sensitivity then can be used to calculate the predictive value of a positive test result if the test is to be applied in a population with a known prevalence of the disease. $^{35}$

Our results indicated that subjects with $\operatorname{ALDH} 2 * 1 / 2$ whose elimination of acetaldehyde was slow reported to have facial flushing PAC regardless of whether the production of acetaldehyde was fast or slow. Subjects with $\operatorname{ALDH} 2 * 1 /{ }^{*} 1$ whose elimination of acetaldehyde was fast still had a $30 \%$ probability of reporting facial flushing. These probabilities were strikingly similar to those of Wall et al. $(n=50)$, in which the probability of reporting flushing was $32 \%$ for subjects with $\mathrm{ALDH} 2 * 1 /{ }^{*} 1$ and $100 \%$ for subjects with $\operatorname{ALDH} 2 * 1 /{ }^{*} 2 .{ }^{28}$ However, in the study by Shibuya et al. ( $n=15)$, the probability of reporting flushing was $0 \%$ for subjects with ALDH2* $1 /{ }^{*} 1,88 \%$ for subjects with ALDH2*1/*2, and $100 \%$ for subjects with ALDH2*2/ $* 2 .^{26}$ In the study by Takeshita et al. (424 men and 100 women), the probability of reporting flushing was $7.9 \%$ (men) and $8.9 \%$ (women) for subjects with ALDH2* $1 /{ }^{*} 1$, 
$84.4 \%$ (men) and $81.3 \%$ (women) for subjects with ALDH2* $1 /{ }^{*} 2$, and $93.1 \%$ (men) and $100 \%$ (women) for subjects with $\mathrm{ALDH} 2 * 2 /{ }^{*} 2 .{ }^{27}$ One possible explanation for the lower probability of reporting flushing in the latter two studies might be due to differences in methods of information collection. Unlike this study and that of Wall et al., in which the PAC sensitivity symptoms were obtained by interviewing, the symptoms were determined by a questionnaire completed by the subjects themselves in the study by Takeshita et al. In the study by Shibuya et al., how the flushing symptom was determined was not described. The possibility of under-reporting of flushing by a selfcompleting questionnaire was supported by the fact that the probability of flushing for men with ALDH2* $2 /{ }^{*} 2$ was not $100 \%$ in the study by Takeshita et al. Several studies indicated that subjects with $\mathrm{ALDH} 2 * 2 /{ }^{*} 2$ were extremely sensitive to alcohol, and studies so far have not found any alcoholics to be ALDH2*2/ $2{ }^{19,36}$

It is interesting to note that Wall et al. ${ }^{28}$ found that the accuracy of investigator-observed flushing is more accurate than interviewing-derived self-reported flushing. For subjects with $\mathrm{ALDH} 2 * 1 /{ }^{*} 2$, both investigator-observed and self-reported flushing rates were $100 \%$. Among 28 subjects with ALDH $2 * 1 /^{*} 1$, only 1 ( $4 \%$ ) was observed to have flushing. Given that the self-reported flushing rate for a given ALDH 2 genotype was so similar in these two studies, we do not believe that the excess self-reported flushing rate is due to a reported error or recall bias. Instead, we think that an individual's self-report of flushing may be based on a different amount or duration of alcohol intake than the amount administered during the observed alcohol test. Another possibility is that a subject's feeling of flushing might include something other than reddening of the skin as observed by an investigator, such as a feeling of heat in the cheeks.

In this study we further explored the possibility that the self-reported flushing of the subject with $\mathrm{ALDH} 2 * 1 /{ }^{*} 1$ might be accounted for by $\mathrm{ADH} 2$ or $\mathrm{ADH} 3$. Our results indicated that subjects with $\mathrm{ALDH} 2^{*} 1{ }^{*} 1$ would have 35$44 \%$ probability of reporting facial flushing only if their production of acetaldehyde by $\mathrm{ADH} 2$ is fast (containing at least one $\mathrm{ADH} 2 * 2$ allele); otherwise, they would have no alcohol-induced flushing. However, ADH3 genotype did not explain the difference in facial flushing for subjects with ALDH $2 * 1 /{ }^{*} 1$ and fast production of acetaldehyde $\left(\mathrm{ADH} 2 * 1 /{ }^{*} 2\right.$ or $\left.\mathrm{ADH} 2 * 2 / * 2\right)$. Therefore, other unidentified genetic or environmental factors (such as individual differences in the amount of alcohol intake) may account for this.

Another important finding of this study is that nausea can help determine whether an alcohol flusher has genotype $\mathrm{ALDH} 2 * 1 / * 1$. Our data indicate that self-reported flushers with $\mathrm{ALDH} 2 * 1 /{ }^{*} 1$ were more likely to have accompanying nausea PAC than self-reported flushers with $\mathrm{ALDH} 2 * 1 /{ }^{*} 2$ regardless of whether nonalcoholic controls were excluded from the analyses or not. Wall et al. ${ }^{28}$ also noted that the probability of self-reporting nausea for sub- jects with $\mathrm{ALDH} 2^{*} 1 /^{*} 1(11 \%)$ was higher than that for subjects with $\mathrm{ALDH} 2 * 1 /{ }^{*} 2(0 \%)$, although the difference was not statistically significant ( $p=0.26$, Fisher's exact test, 2-tailed).

Thus, it seems that transient elevation of acetaldehyde is responsible for the facial flushing $\mathrm{PAC}$, and our results indicated that genetic polymorphisms of both ALDH2 and ADH2 contribute significantly to the presence of facial flushing. However, the role of acetaldehyde in causing facial flushing has been controversial. ${ }^{37} \mathrm{~A}$ study found that blood levels of acetaldehyde following an acute dose of alcohol were higher in nonabstinent alcoholics than in nonalcoholic controls, and the blood levels of acetaldehyde in the alcoholics after 2 weeks of abstinence returned toward levels comparable to those observed in nonalcoholics. ${ }^{38}$ However, we do not think that inclusion of chronic alcoholics can account for all the findings in this study because our results remained the same if only alcoholics were included for the analyses. The consistency of the findings and possible biochemical mechanisms for the generation of nausea after alcohol consumption warrants further investigation.

There are other implications of these findings. First, self-report of low response to alcohol intake has been found to predict a higher risk for alcoholism among $\mathrm{Cau}-$ casian sons of alcoholics. ${ }^{39,40}$ Since ALDH2*2 was not found and $\mathrm{ADH} 2 * 2$ was rare $(4 \%)$ among Caucasians, ${ }^{41}$ the individual variation in flushing after alcohol challenge in these subjects may be due to polymorphisms of ADH3 or other unexamined alcohol-metabolizing genes. Second, predicting the genotype of ALDH2 on the basis of selfreported flushing and nausea can help identify subjects at increased risk for alcoholism. Our data indicate that Han subjects at high risk for alcoholism are those who do not have flushing $\left(100 \%\right.$ to be $\left.\mathrm{ALDH} 2^{*} 1 /{ }^{*} 1\right)$ or have flushing accompanied by nausea (predictive probability of being ALDH $2 * 1 /{ }^{*} 1$ was $71 \%$ ). These results will be useful for selecting a target population for an alcoholism prevention program.

\section{ACKNOWLEDGMENT}

The authors would like to acknowledge the hard work and excellent performance of our research assistants E.W. Loh, H.T. Hsu, Y.C. Chur, and H.R. Yang. The authors would also like to thank the staff at Chinshan Health Station and the Health Screening Ward at NTU Hospital for helping us coordinate the recruitment of subjects, Dr. S.J. Yin for cross-validating our genotyping methods, and Dr. C.K. Hsiao for the derivation of the conditional probabilities.

\section{REFERENCES}

1. Wolff PH: Ethnic differences in alcohol sensitivity. Science 175: $449-450,1972$

2. Chan AWK: Racial differences in alcohol sensitivity. Alcohol Alcohol 21:93-104, 1986

3. Akusta PD, Sue S, Zane NWS, Nakamura CY: Ethnic differences in alcohol consumption among Asians and Caucasians in the United 
States: An investigation of cultural and physiological factors. J Stud Alcohol 50:261-267, 1989

4. Higuchi S, Parrish KM, Dufour MC, Towle LH, Harford TC: The relationship between three subtypes of the flushing response and DSM-III alcohol abuse in Japanese. J Stud Alcohol 53:553-560, 1992

5. Li HZ, Rosenblood L: Exploring factors influencing alcohol consumption patterns among Chinese and Caucasians. J Stud Alcohol 55:427433,1994

6. Nakawatase TV, Yamamoto J, Sasao T: The association between fast-flushing response and alcohol use among Japanese Americans. J Stud Alcohol 54:48-53, 1993

7. Schwitters SY, Johnson RC, McClearn GE, Wilson JR: Alcohol use and the flushing response in different racial-ethnic groups. J Stud Alcohol 43:1259-1262, 1982

8. Suwaki $\mathrm{H}$, Phara $\mathrm{H}$ : Alcohol-induced facial flushing and drinking behavior in Japanese men. J Stud Alcohol 46:196-198, 1985

9. Chen C-C, Hwu H-G, Yeh E-K, Morimoto K, Otsuki S: Aldehyde dehydrogenase deficiency, flush patterns and prevalence of alcoholism: An interethnic comparison. Acta Med Okayama 45:409-416, 1991

10. Nagoshi CT, Dixon LK, Johnson RC, Yuen SHL: Familial transmission of alcohol consumption and the flushing response to alcohol in three Oriental groups. J Stud Alcohol 49:261-267, 1988

11. Schwitters SY, Johnson RC, Johnson SB, Ahern FM: Familial resemblances in flushing following alcohol use. Behav Genet 12:349-352, 1982

12. Johnson RC, Nagoshi CT, Schwitters SY, Bowman KS, Ahern FM, Wilson JR: Further investigation of racial/ethnic differences and of familial resemblances in flushing response to alcohol. Behav Genet 14:171-178, 1984

13. Park JY, Huang Y-H, Nagoshi CT, Yuen S, Johnson RC, Ching CA, Bowman KS: The flushing response to alcohol use among Koreans and Taiwanese. J Stud Alcohol 45:481-485, 1984

14. Stamatoyannopoulos G, Chen S-H, Fukui M: Liver alcohol dehydrogenase in Japanese: High population frequency of atypical form and its possible role in alcohol sensitivity. Am J Hum Genet 27:789-796, 1975

15. Korsten MA, Matsuzaki S, feinman L, Lieber CS: High blood acetaldehyde levels after ethanol administration: Difference between alcoholic and nonalcoholic subjects. N Engl J Med 292:386-389, 1975

16. Goedde HW, Harada S, Agarwal DP: Racial differences in alcohol sensitivity: A new hypothesis. Hum Genet 51:331-334, 1979

17. Smith M: Genetics of human alcohol and aldehyde dehydrogenases. Adv Hum Genet 15:249-290, 1986

18. Bosron WF, Li T-K: Genetic polymorphism of human liver alcohol and aldehyde dehydrogenases, and their relationship to alcohol metabolism and alcoholism. Hepatology 6:502-510, 1986

19. Enomoto N, Takase S, Yasuhara M, Takada A: Acetaldehyde metabolism in different aldehyde dehydrogenase-2 genotypes. Alcohol Clin Exp Res 15:141-144, 1991

20. Harada S, Agarwal DP, Goedde HW, Tagaki S, Ishikawa B: Possible protective role against alcoholism for aldehyde dehydrogenase isozyme deficiency. Lancet ii:827, 1982

21. Thomasson HR, Edenberg HJ, Crabb DW, Mai XL, Jerome RE, Li TK, Wang SP, Lin YT, Lu RB, Yin SJ: Alcohol and aldehyde dehydrogenase genotypes and alcoholism in Chinese men. Am J Hum Genet 48:677-681, 1991

22. Thomasson HR, Crabb DW, Edenberg HJ, Li TK, Hwu H-G, Chen C-C, Yeh E-K, Yin S-J: Low frequency of the ADH2*2 allele among Atayal natives of Taiwan with alcohol use disorders. Alcohol Clin Exp Res 18:640-643, 1994
23. Higuchi S, Matsushita S, Murayama M, Takagi S, Hayashida M: Alcohol and aldehyde dehydrogenase polymorphisms and the risk for alcoholism. Am J Psychiatry 152:1219-1221, 1995

24. Maezawa Y, Yamauchi M, Toda G, Suzuki H, Sakurai S: Alcoholmetabolizing enzyme polymorphisms and alcoholism in Japan. Alcohol Clin Exp Res 19:951-954, 1995

25. Chen WJ, Loh EW, Hsu Y-PP, Chen C-C, Yu J-M, Cheng ATA: Alcohol-metabolizing genes and alcoholism among Taiwanese Han Men: Independent effect of $\mathrm{ADH} 2, \mathrm{ADH} 3$, and $\mathrm{ALDH} 2$. Br J Psychiatry 168: 762-767, 1996

26. Shibuya A, Yasunami M, Yoshida A: Genotypes of alcohol dehydrogenase and aldehyde dehydrogenase loci in Japanese alcohol flushers and nonflushers. Hum Genet 82:14-16, 1989

27. Takeshita T, Morimoto K, Mao X-Q, Hashimoto T, Furuyama J-I: Characterization of the three genotypes of low $\mathrm{K}_{\mathrm{m}}$ aldehyde dehydrogenase in a Japanese population. Hum Genet 94:217-223, 1994

28. Wall T, Thomasson HR, Ehlers CL: Investigator-observed alcoholinduced flushing but not self-report of flushing is a valid predictor of ALDH2 genotype. J Stud Alcohol 57:267-272, 1996

29. Chen WJ, Loh EW, Hsu Y-PP, Chen C-C, Yu J-M, Cheng ATA: Dopamine D2 receptor gene and alcoholism among four aboriginal groups and Han in Taiwan. Am J Med Genet (Neuropsychiatr Genet) 74:129-136, 1997

30. American Psychiatric Association: Diagnostic and Statistical Manual of Mental Disorders. 3rd ed rev. Washington, DC, American Psychiatric Association 1987

31. Cheng TA, Chen WJ: Alcoholism among four aboriginal groups in Taiwan: High prevalences and their implications. Alcohol Clin Exp Res 19:81-91, 1995

32. Xu Y, Carr L, Bosron WF, Li T-K, Edenberg HJ: Genotyping of human alcohol dehydrogenases at the $\mathrm{ADH} 2$ and $\mathrm{ADH} 3$ loci following DNA sequence amplification. Genomics 2:209-214, 1988

33. Walzer C, Turler H, Balant L, Golaz O, Hochstrasser DF, Monteiro $\mathrm{M}$, von Wartburg J-P; Determination of human alcohol dehydrogenase and acetaldehyde dehydrogenase genotypes by single strand conformation polymorphism in discontinuous buffer electrophoresis. Electrophoresis 14:566-569, 1993

34. Tu G-C, Israel Y: A new approach for the rapid detection of common and atypical aldehyde dehydrogenase alleles. Eur J Clin Chem Clin Biochem 31:591-594, 1993

35. Sackett DL, Haynes RB, Guyatt GH, Tugwell P: Clinical Epidemiology: A Basic Science for Clinical Medicine. 2nd ed. Boston, Little, Brown 1991

36. Thomasson HR, Crabb DW, Edenberg HJ, Li TK: Alcohol and aldehyde dehydrogenase polymorphisms and alcoholism. Behav Genet 23:131-136, 1993

37. Chao HM: Alcohol and the mystique of flushing. Alcohol Clin Exp Res 19:104-109, 1995

38. Di Padova C, Worner TM, Lieber CS: Effect of abstinence on the blood acetaldehyde response to a test dose of alcohol in alcoholics. Alcohol Clin Exp Res 11:559-561, 1987

39. Schuckit MA: Low level of response to alcohol as a predictor of future alcoholism. Am J Psychiatry 151:184-189, 1994

40. Schuckit MA, Smith TL: Assessing the risk for alcoholism among sons of alcoholics. J Stud Alcohol 58:141-145, 1997

41. Gilder FJ, Hodgkinson S, Murray RM: ADH and ALDH genotype profiles in Caucasians with alcohol-related problems and controls. Addiction 88:383-388, 1993 